\title{
Um Histórico de Luta: A Juventude Popular Católica e a Comissão Pastoral da Terra em Alagoas na trajetória de Carlos Lima ${ }^{\mathrm{I}}$
}

\section{Alex Benedito Santos Oliveira ${ }^{2}$}

Nas Alagoas, pelos locais que andamos, a pobreza acompanha o povo camponês. Isto é reflexo da estrutura econômica e social do estado que ainda é assentada nos projetos de concentração de terra e exploração do trabalhador. Esses projetos minaram as formas de desenvolvimento social e econômico que poderiam livrar da miséria as várias famílias de trabalhadores do campo. No espaço geográfico alagoano homens e mulheres lutam em vários momentos sozinhos, tendo nas próprias mãos os únicos instrumentos de busca pela sobrevivência contra a pobreza provocada pelo latifúndio. Objetivando mudar esta realidade, algumas instituições cristãs adentram o campo social e político. Assim, iniciaram a participação neste meio, na forma de auxílio, visando mudar a condição de vida em que estes trabalhadores rurais estavam. Estas instituições passaram a atuar na luta pela democratização da terra, com a intenção de transformar o panorama da concentração fundiária e do domínio de poucos indivíduos, socializando o uso da terra para as classes despossuídas e, consequentemente, diminuindo o processo empobrecimento de muitos trabalhadores.

Em Alagoas as principais terras agricultáveis estão alocadas para cerca de $5 \%$ da população mais rica do estado. Este percentual representa a parcela que concentra parte total dos bens de capital. Este grupo seleto proporciona a exclusão de mais de $70 \%$ das pessoas com condições de trabalho, de usarem um bem social, que é a terra, para produzirem bens alimentícios. Tal produção proporcionaria o barateamento de alimentos e a manutenção de

\footnotetext{
${ }^{\mathrm{I}}$ Entrevista realizada na Arquidiocese de Maceió, em de II de maio de 2016.

${ }^{2}$ Graduado em História pela Universidade Federal de Alagoas, Mestre em História Social pela UFAL, atuando principalmente em pesquisas nos campos da luta de classes, movimentos sociais ligados à Igreja Católica e ditadura militar no Brasil, dando ênfase as ações desempenhadas por grupos subalternos de trabalhadores no período militar brasileiro.
}

Recebido em 30 de agosto de 2016 e aprovado para publicação em Io de outubro de 2016 
vários postos de emprego no estado. Esta concentração fundiária tem a proteção de estruturas estatais, forma clássica de domínio da propriedade privada frente ao trabalhador.

Buscando mudar este quadro social observamos as ações realizadas pela Igreja Católica no campo, em Alagoas. Tendo em vista a melhoria da distribuição de terra e a melhor participação da classe trabalhadora na política e na economia. Assim, objetiva-se por meio desta entrevista, entender como a instituição católica formou quadros de militantes para atuarem nesta área. A formação baseada em estruturas de assistência social e política aglomeravam e orientavam vários jovens para as ações de militância por direitos sociais. Para a compreensão destas ações foram analisadas duas estruturas de formação política e ideológica: a Comissão Pastoral da Terra (CPT) e a Pastoral da Juventude do Meio Popular (PJMP). Estas organizações visavam aglomerar e instruir a juventude politicamente, sobre as condições sociais que o povo "excluído" vivia.

No âmbito das pastorais compreende-se como os jovens que militavam foram preparados e introduzidos nas lutas sociais e a importância da preparação ideológica, via Pastoral da Juventude do Meio Popular, para serem introduzidos em pastorais que apresentavam uma função mais efetiva na luta politica como a CPT. Os treinamentos foram fundamentais para canalizar o participante dentro da realidade social e política da localidade. Nesta análise compreende-se que o aprendizado pela ação, característico da Teologia da Libertação, para a Igreja, exerceu uma função importante como meio de formação política e como forma de avaliação do participante. Durante estas ações os jovens eram avaliados sobre seu caráter de ação e, posteriormente, eram convidados, ou não, a comporem pastorais com planos de ação para mudança social mais efetiva.

Tendo estes problemas em mente, esta entrevista busca entender as ações promovidas pela Pastoral Juventude do Meio Popular e sua a influência nas atividades instrutivas dos conselhos pastorais, implementadas na realidade concreta da sociedade alagoana. Os jovens que passaram por esta experiência foram introduzidos na Comissão Pastoral da Terra em Alagoas. Lá puderam desenvolver em caráter efetivo, as ações de transformações sociais, com suporte das reflexões adquiridas enquanto participantes da juventude popular. Por fim, percebe-se uma dialética nas atividades exercidas pela Pastoral da Terra através dos processos assentados em conflitos sociais, baseados na busca por acesso à terra para reforma agrária, entre camponeses, grileiros e donos de usinas de açúcar. Seria possível, portanto, ter uma 
visão de conjunto sobre os mecanismos de atividade política da Igreja, junto à sociedade, e sobre o cotidiano de luta social promovida pela CPT, junto aos camponeses em Alagoas.

Esta entrevista é parte de um estudo mais amplo sobre as formas e ações de intervenção que a Igreja Católica executou em Alagoas mediante as atividades dos movimentos sociais ligados a ela. O envolvimento da Igreja Católica com os movimentos populares deu-se, mais fortemente, no contexto pós-Vaticano II (I962-I965), sob a influência das experiências da Igreja na América Latina, intensificadas com o influxo da Teologia da Libertação (TL) e das pastorais sociais. Em Alagoas, ainda há um vasto campo de pesquisa sobre tais relações, em especial, para as décadas de 1970 a 2000. As experiências da chamada "Igreja Popular" no Brasil foram postas à prova durante o Papado de João Paulo II, que tendeu a criticar e condenar o avanço da TL e das pastorais mais engajadas, o que acarretou conflitos e tensões entre parte da hierarquia e a militância. A trajetória da militância católica que participou ativamente deste processo torna-se, pois, um instrumento interessante para a verificação das reflexões apontadas acima.

O entrevistado, Carlos Lima, atualmente é coordenador da Pastoral da Terra em Alagoas, graduado e mestre em História pela Universidade Federal de Alagoas. Sua formação política oriunda da sua experiência como católico, em específico com as atividades sociais realizadas pela paróquia do Jacintinho, na capital Maceió, junto ao núcleo da Juventude Popular e do Teatro Popular nos anos 1990.

\section{Como funcionavam os Conselhos Pastorais dentro da comunidade?}

$\mathrm{Na}$ nossa comunidade os Conselhos Pastorais se reuniam mensalmente. Ele tinha a representação de todos os grupos; além do Conselho tínhamos a Assembleia Geral da Comunidade. $\mathrm{O}$ padre era um facilitador, um instrutor, mas não tinha a palavra final sobre as ações da comunidade; ela quem decidia e resolvia os grandes problemas. Nós tivemos padres que contribuíram com isso como os padres Gustavo e Petrúcio Ramires. Eles eram pessoas que entendiam esse processo democrático de participação dos cristãos. As decisões eram tomadas pelo conselho pastoral comunitário que dava esse poder a quem participava da vida da comunidade ativamente. Isso no meu entendimento era fundamental; lamentável que com o tempo o conselho perdeu força. Eles começaram a perder força por que a Igreja entrou no processo com o entendimento que eram necessárias reações para evitar a saída dos cristãos 
católicos. Um dos motivos foi o fortalecimento da instituição Igreja dando maior destaque as ações do padre, não dos fiéis. Esse foi o modelo de Igreja que se fortaleceu nos anos I990, e predomina até hoje. Apesar de termos um Papa "progressista”, preocupado com o mundo, com as pessoas, ainda temos uma Igreja voltada para si mesma.

Quais as atividades promovidas pela Igreja influenciaram na sua formação política do militante?

A Igreja promovia atividades que contribuíram decisivamente para a minha formação social. A Igreja entendia que era preciso ter cristãos informados da relação social e que pudessem modificar a sociedade. Neste período a instituição agia de forma diferente, existiam religiosos progressistas preocupados com o povo, como Dom Hélder Câmara, Dom Francisco, Dom José Maria Pires, Dom Miguel. Visando compreender o que acontecia no meio social as formações instrucionais eram fundamentais. Existia a formação na igreja local, na Arquidiocese, e no conselho Regional Nordeste II. Participei de um grupo de teatro chamado Nossa História, fundado no Jacintinho. Ele tinha uma relação com o Regional Nordeste II que compreendia as arquidioceses de Alagoas, Pernambuco, Paraíba e Rio Grande do Norte. No Regional havia o Setor de Comunicação com um espaço dedicado ao teatro popular. Posteriormente, quando Dom José Cardoso, um bispo de linha conservadora, assumiu a Regional Nordeste II uma das medidas dele foi extinguir o setor de teatro popular, em seguida acabou a Pastoral Rural. Demitiu toda a assessoria, proibiu a atuação da Pastoral Rural; neste momento emergiu de forma independente a CPT. Havia uma relação entre a CPT e a Pastoral Rural; a partir desse fato se cria formalmente a CPT no Regional Nordeste II. Era uma igreja preocupada com o pobre, não a figura do "bom samaritano" que todo mundo exalta, mas com a figura do pobre, aquele que está caído, essa era a preocupação da Igreja.

\section{Quais eram as atividades instrutivas desenvolvidas por este grupo teatral?}

$\mathrm{Na}$ nossa comunidade fazíamos atividades instrutivas com a técnica do teatro de rua. Fizemos um espetáculo chamado, "Teatro Imagem”, no Dia da Mulher. Levamos uma jovem, com uma coleira e com uma maquiagem que o olho mostrava que ela tinha sofrido agressão. E o marido dela pegava-a pela coleira; fomos ao Centro de Maceió e entrávamos nas lojas. Em 
pouco tempo tinha uma multidão atrás de nós, todos gritando: "tem que matar"! A polícia foi chamada. Nós tínhamos um suporte técnico, além dos dois atores. Cheguei perto do policial e informei: "não se preocupe é uma encenação de teatro por causa do dia da mulher, neste período os homens oferecem flores, mas nós sabemos que essa realidade de agressão acontece nos diversos lares”. Ele gostou da ideia, mas continuou a nos seguir. Quando chegamos na praça Deodoro ela retirou a coleira e a maquiagem e relatamos que fazíamos parte de um grupo de teatro e queríamos discutir a questão da mulher na sociedade. A Campanha da Fraternidade daquele período [CFI990 - Mulher e Homem, imagem de Deus] teve como tema este debate e o que nos auxiliou a produzir esse espetáculo. Nós trabalhamos várias expressões de mulheres, desde os primórdios até chegar em Margarida Alves, uma sindicalista, que foi assassinada na Paraíba [Alagoa Grande, I2 de agosto de I983].

\section{Foi dado apoio pela paróquia do Jacintinho ou da Arquidiocese para a formação deste grupo teatral?}

O grupo de teatro recebia apoio da paróquia do Jacintinho, tínhamos o salão paroquial para ensaiar. Em contrapartida participávamos das celebrações litúrgicas da paróquia, era comum fazermos encenações para a comunidade. Em nível de Arquidiocese, ela nos fornecia recursos financeiros para viajarmos. Nós percorremos vários estados com temas sociais como a dengue, assim muitas prefeituras nos convidavam para apresentar nossas atividades nos municípios.

Vocês receberam algum treinamento instrucional da Igreja para compor o grupo de teatro popular?

O grupo teatral recebia formação da Igreja, isto por meio do Setor de Comunicação no qual o teatro era vinculado. Você tinha formação com atores; eles nos instruíam como escrever textos e estabeleciam encontros dos grupos de teatro populares ligados à Igreja para que experiências de lutas sociais fossem trocadas. Você tinha uma organização que conviveu por 
algum tempo em plena atividade política, até que Dom José Cardoso ${ }^{3}$ extinguiu esse setor, cortando os recursos que viabilizavam as atividades. Contrariando esta ação, a organização teatral continuou por algum tempo, mediante o apoio com os recursos locais da paróquia.

\section{Quais os reflexos destes treinamentos na formação ideológica do grupo?}

Essa formação refletiu nos indivíduos enquanto seres políticos. Eu gosto de uma frase que dizia assim: "quando a gente pensa no que vai fazer, a gente faz melhor". Esses treinamentos foram no sentido de dizer assim: você tinha que ter um conhecimento político do que era a sociedade, qual a finalidade do impacto político projetado pela peça. Eram processos construídos no sentido de oferecer um reflexo político a partir da arte, questionando a sociedade que vivíamos na época.

\section{Em que momento da militância cultural surge a proposta de integrar a Pastoral da Terra?}

Em 1994 recebi a proposta de integrar a Pastoral da Terra, fui convidado pelo padre italiano Aldo Jaelson, pároco de Colônia Leopoldina. Ele era membro da Pastoral da Terra em Alagoas. Conhecíamos havia algum tempo, pois sempre fui ligado a Pastoral da Juventude do Meio Popular. Ele formulou o convite para que eu integrasse a CPT.

\section{Qual era o contexto da Igreja em Alagoas no período que você iniciou a militância na CPT?}

Quando comecei a minha militância na CPT a Igreja era muito forte, desenvolvendo grandes lutas sociais no Estado. Ela foi fundamental na primeira grande ocupação dos semteto na Chã de Bebedouro. A Igreja participou com a finalidade de fortalecer e expandir os grupos de esquerda, o que denominamos de esquerda católica. Existia essa preocupação de se envolver no mundo político de construir ferramentas para os trabalhadores lutarem. Esse foi o contexto quando cheguei na Pastoral da Terra, o conflito fazia parte da vida do cristão militante, do cristão católico.

\footnotetext{
${ }^{3}$ Bispo de linha conservadora que substituiu Dom Hélder Câmara no arcebispado de Recife e Olinda em I985 e cuidou em seguir as determinações do Papa João Paulo II para desmontar as estruturas progressistas da Igreja católica no Brasil. Foi presidente do Regional Nordeste II entre I987 e I99I.
} 
Durante este período de ocupação dos sem teto, quais as atividades promovidas pela Igreja, junto ao povo?

A Igreja durante a ocupação contribuiu primeiro com a presença. As pessoas gostavam e se sentiam seguras, pois tinham a presença de padres e religiosas dentro daquela ocupação, apoiando a sua ação em defesa de moradia. Ocorreu também uma interação política e religiosa neste período, que é preservada até hoje, pelo menos com a CPT, que foi a aproximação com a Igreja Batista do Pinheiro, pela representação do pastor Marcos. Eram realizadas celebrações e visitas aos barracos conjuntamente por religiosos de ambas as igrejas. Isto durante todo o processo de ocupação e, principalmente, nos momentos de pressão e perseguição que o governo Geraldo Bulhões [I99I-I995] exerceu sobre os moradores. Participávamos daquela luta pois acreditávamos que aquela ação representava uma mudança na estrutura.

\section{Havia atividades instrucionais da Igreja com os sem-teto?}

A Igreja tinha a preocupação de deixar claro que o fato de ocupar não era um crime. Informando aos ocupantes que um direito foi negado a eles, o direito à moradia. Expressando que era justa a ocupação, a Igreja sempre teve a preocupação de tirar esse peso deles. Muitos pobres carregavam o peso que ocupar uma fazenda improdutiva para construir um assentamento ou ocupar um terreno para construir casas era um "pecado", porque estava "roubando" a terra de alguém. A Igreja informava que era um direito que ele tinha e o Estado lhe negou, a elite negou. A instituição se preocupou em dar legitimidade aquela ação.

\section{Qual o histórico de ocupação e luta por terra em Alagoas praticado pela CPT?}

Vou descrever em partes o histórico da CPT em Alagoas. No meio da década de 1990 começa uma reestruturação do setor sucroalcooleiro do Estado de Alagoas. Eles precisavam concentrar a produção, melhorar a competitividade. A produtividade deles estava sendo questionada, pois não conseguiam disputar com outros centros produtores de açúcar e álcool. A reestruturação do setor expandiu os canaviais para as áreas do tabuleiro, somado a isso, tem que algumas empresas que não se modernizaram dentro do capitalismo; continuaram sendo unidade familiar, não empresarial, assim não suportando as mudanças na economia. Neste 
contexto foi gerado um desmonte de algumas dessas unidades industriais; não significa que quebraram. Com isso surge a oportunidade de novas terras. Neste momento ocorre uma disputa entre grileiros de terras e as famílias que foram demitidas do corte da cana, isso aconteceu intensamente no Vale do Paraíba. Os usineiros visaram apagar a ligação de trabalho de várias famílias, com estas unidades industriais. Assim, cometeram um dos crimes trabalhistas que até hoje as várias gerações de trabalhadores estão pagando. Ela que foi a derrubada de 50 mil casas, que atrapalham a identificação se realmente aquele trabalhador que reivindicava parte das terras, realmente trabalhou naquela usina. Cícero Péricles no seu livro fala em 40 mil, isso como dado oficial. Mas se fala em 50 mil casas entre 1990 e I995. Nós temos em 1993 a primeira ocupação da fazenda Conceição, em Porto Calvo. Neste período, surgiram outras ocupações em massa de terra, como nas regiões de Branquinha, Atalaia, União dos Palmares, Maragogi. Foi o boom das ocupações no Estado de Alagoas, e também com elas os conflitos e ameaças de morte e companheiros assassinados. Nós da CPT passamos por essa dificuldade, até 1997 nós apoiávamos de forma assistencial a luta dos sem-terra. As paróquias se envolviam arrecadando remédios, alimentos, indo para as ocupações celebrar. Depois de 1998 com o advento do Flor do Bosque a CPT começou a direcionar o trabalho mais voltado em defesa da reforma agrária. A CPT como herança da Pastoral Rural, nasceu dentro do canavial, trabalhando as oposições sindicais para tomar os sindicatos dos dirigentes pelegos $^{5}$, comprometidos com o latifúndio canavieiro. Ela combateu de forma inteligente e recorrente a questão da violência no campo. Uma violência institucionalizada, um "instituto" chamado "violência no Estado de Alagoas". A CPT fez grandes denúncias e promoveu a criação do Fórum Permanente Contra a Violência na década de I990.

\section{Como eram as articulações feitas pela Igreja alagoana para a retomada dos sindicatos rurais das administrações "pelegas"?}

Para entender como se deu as articulações da Igreja Católica em Alagoas é necessário saber o seu histórico. Inicialmente algumas paróquias, dirigidas por padres de linha progressista, começaram a perceber que não eram naturais a exploração e a violência que os

\footnotetext{
${ }^{4}$ Área de assentamento de trabalhadores ligados a Comissão Pastoral da Terra.

${ }^{5}$ Indivíduos que delatavam trabalhadores ou ficavam omissos quanto a realidade de exploração que os trabalhadores viviam.
} 
canavieiros passavam nas usinas. Eu lembro que Dom Edvaldo ${ }^{6}$ uma vez disse que viu uma criança de chupeta na boca cortando cana. E comentou para nós que naquele momento percebeu que "o açúcar não era tão doce", e ainda disse mais: "A CPT converteu-me, mostrando como é opressora a estrutura da cana”. Eram inevitáveis as paróquias não perceberem a realidade social do povo canavieiro, umas fecharam os olhos como faziam os sindicatos, outras se aprofundaram para entender e combater este processo de exploração. Aí temos que destacar duas missões católicas importantes na Zona da Mata: a missão canadense em União dos Palmares com padre Emílio, padre Donald, irmã Léa e padre Leso; e a missão italiana em Colônia Leopoldina, Novo Lino e Joaquim Gomes que tinham com coordenadores os padres Aldo e Luís Canal. Esse último na minha avaliação era o teórico, o intelectual que sabia se mexer, envolvia-se com a formação. O padre Aldo era o militante, o político, o padre dos trabalhadores, dos pobres. Eles perceberam que a opressão não iria acabar facilmente porque os sindicatos que deveriam ser os instrumentos de luta dos trabalhadores frente a exploração, estavam nas mãos dos pelegos. A alternativa para mudar esta relação foi retirar os sindicatos das mãos dos pelegos nesta região. Neste período participamos das eleições sindicais desta região, prestando apoio instrucional a chapa oposicionista. Fato que desagradou aos patrões e sindicalistas ligados a eles, desencadeando muitas perseguições contra nós. Essa situação ocorreu quando fizemos oposição ao processo de eleição sindical em Campestre. A oposição quando perdeu, passou a nos ameaçar de morte, forçando a CPT a deixar de atuar no município. A irmã Carmem que é da Congregação das Irmãs Santa Virgem de Assunção, teve que ser retirada da área porque havia uma perseguição muito clara. Mais tarde, padre Aldo e depois padre Luís Canal, tiveram que deixar a região e a Arquidiocese de Maceió, para não morrerem. A violência e os assassinatos eram os caminhos escolhidos pelas elites açucareiras, para impedir nossas ações. Comportamentos que não devem ser aceitos mais por nossa sociedade.

Como era debatida a questão das perseguições e mortes de militantes rurais pela Igreja alagoana?

\footnotetext{
${ }^{6}$ Bispo de linha progressista que incentivou o desenvolvimento das ações da CPT em Alagoas. Arcebispo de Maceió entre 1986 a 2002.
} 
Para discutir as perseguições e as mortes a CPT realizou encontros sobre violência. Com isto, fez surgir a Assessoria Jurídica da CPT, que tinha por finalidade acompanhar os sindicatos e as oposições sindicais, dando uma garantia jurídica aos trabalhadores. A assessoria jurídica foi resultado dos encontros sobre violência realizados no Fórum Permanente Contra a Violência. Quando entrei na CPT participei de um encontro em Colônia Leopoldina, uma oficina que a gente fez junto com a FASE. Durante a reunião uma mulher falou assim: "o meu filho chegou ontem com um braço". Eu pensei fosse um braço de boneca, mas era um braço de gente. A criança havia encontrado no canavial e levou-o para casa mesmo fedendo. O canavial sempre foi local de muita violência. Outro relato dos encontros: um trabalhador que tinha entrado na Justiça contra a usina, sofreu um atentado a bala, ele sobreviveu e procurou a subdelegacia da usina para fazer a denúncia criminal. Havia naquele período subdelegacias ${ }^{7}$ nas usinas no sentido de proteger o capital e o poder senhorial. $\mathrm{O}$ subdelegado o chamou e perguntou se ele havia processado a usina; o trabalhador respondeu: que sim. Neste momento começou uma discussão e o trabalhador foi hostilizado pelo subdelegado que atirou no trabalhador. Posteriormente o trabalhador procurou a CPT para intercedermos. Procuramos o secretário de segurança à época, ele perguntou ao trabalhador: "qual a distância que atiraram em você? O trabalhador faz uma referência a parede, daqui para aquela parede”. Ele diz: "não se pode errar um tiro numa distância tão pequena”. Esse era o clima que se vivia naquele período. Muitos crimes como o assassinato do Chico do Sindicato de Atalaia e ninguém foi condenado, e nem processos foram abertos, porque todo mundo sabia quem era o mandante. Nos últimos anos essa prática diminuiu, porque temos uma sociedade em rede, mais estruturada. As denúncias não ficam na localidade que o crime ocorre como acontecia antes. A CPT cumpriu um papel fundamental neste sentido, por estar junto aos canavieiros. Ela colocou para o conhecimento da sociedade, não só em Alagoas, mas a nível nacional e internacional a realidade de violência em Alagoas.

Qual o histórico de conquista pela terra da CPT dos anos 1990 a contemporaneidade, junto com os trabalhadores?

\footnotetext{
${ }^{7}$ Estrutura disponibilizada pela Secretaria de Segurança Pública para proteger e dar assistência a usineiros nas áreas rurais da usina.
} 
$\mathrm{Na}$ verdade, as conquistas são das famílias. Imagine uma sociedade açucareira como a nossa em que o canavial é a coisa mais importante. Você tem um grupo de famílias que tem coragem de ocupar um imóvel improdutivo, que não esteja sendo utilizado para o plantio, mas é uma área da cana. O protagonismo dessas famílias é o essencial, sem elas não existiria a CPT, não existiria o movimento dos trabalhadores rurais sem-terra. Depois a década de 1990 é a das grandes conquistas, do fortalecimento do movimento, das grandes ocupações, dos grandes eventos. O período de 2000 até 2003, ainda acontece ocupações com certa facilidade, mas infelizmente coincide com a paralisação da reforma agrária com os mandatos presidenciais do Partido dos Trabalhadores. Neste período foi retirada da pauta social a reforma agrária na minha avaliação e da Pastoral da Terra, por conta da necessidade da governabilidade, das alianças partidárias, situação determinada pela relação com a bancada ruralista. Interação assentada no seguinte acordo: a reforma agrária deve beneficiar o agronegócio. Neste balcão de negócios ainda tem à frente do Ministério da Agricultura Kátia Abreu, conhecida como a “dama do desmatamento". Infelizmente na atualidade diminuiu as áreas de assentamento. $\mathrm{Na}$ verdade, nunca tivemos reforma agrária, tínhamos política de assentamento, ou seja, distribuição de pequenas áreas para produção. Mas nem essa política o PT conseguiu expandir, isso foi muito ruim, porque foi na mão da esquerda que esse processo estagnou.

\section{Como você caracteriza esta política de assentamento em Alagoas?}

Posso exemplificar a política de assentamento em Alagoas com uma fala expressa durante o seminário da apresentação do Grande Complexo Agrisa ${ }^{8}$, com II mil hectares de terras adquiridos, a antropóloga do INCRA informou assim: “50\% das terras adquiridas não são agricultáveis. Nós estamos jogando alguns milhões fora em terras que não são agricultáveis. $\mathrm{Na}$ verdade, há mais benefício aos latifundiários, por ganharem dinheiro e se livrarem de terras inúteis". Não ocorreu avanço na democratização do uso da terra. Elas que eram distantes, cansadas, mortas, que precisam ser reanimadas, e em localidades que precisa de infraestrutura como: estradas, água potável, eletricidade, que poderiam assim atender as necessidades das famílias camponesas. Este processo diminuiu a tensão social porque assentava as famílias, mas, na verdade, estavam favorecendo aos fazendeiros que queriam se livrar daquelas terras, pois não dava lucro. Isso é tão nítido que o governo ainda criou o

\footnotetext{
${ }^{8}$ Área industrial de produção agrícola localizada na região de Penedo-AL.
} 
programa de Crédito Fundiário, que foi o verdadeiro mercado de terra. Hoje tem muitas famílias endividadas por meio desta forma de obtenção de crédito que beneficiou apenas banqueiros. A CPT e o MST denunciaram esse programa, mas é uma realidade absurda em Alagoas. Os recursos do governo federal injetados nos estados e nos institutos de terra se tornaram uma grande imobiliária desse processo.

\section{$\mathrm{Na}$ atualidade quais as ações desenvolvidas pela CPT juntos aos trabalhadores rurais?}

A CPT atua junto aos trabalhadores rurais da seguinte forma: temos uma equipe na Mata Norte, no Litoral Norte e Sertão. Nestas regiões temos o que chamamos de encontro dos coordenadores em áreas de conflito. Nós temos uma estrutura de formação para militantes, onde observamos os que estão se destacando, os que têm interesse em aprofundar essa questão ideológica da luta pela terra. Realizamos atividades políticas com eles, por meio de assembleias estaduais da CPT, sempre com um tema social da nossa localidade, com prévio planejamento. Nós fazemos atividades que garantem a nossa "pastoralidade", caso das celebrações, romarias da terra, das águas, o jejum. Momentos que a gente exerce, por causa da relação com a Igreja, com o evangelho, por sermos militantes cristãos.

\section{O homem do campo hoje está mais consciente da luta política em nossa sociedade?}

Analisar a consciência política do homem do campo é complicado. Acho que é difícil aferir isso, acho que teve uma diminuição significativa dos momentos de formação. Acho que grandes instituições abriram mão disso: o PT, a CUT. Eles apostaram em eventos de multidão, de mostrar força. Enquanto isso a racionalidade, o debate, a qualidade, a teoria, perdeu espaço. Entramos na era da multidão, o que importa é a multidão. $\mathrm{Na}$ minha avaliação isso é um equívoco porque é preciso ter gente preparada politicamente, no nosso caso, biblicamente, para atuar na sociedade. Uma atuação sem base é uma atuação débil, esses anos têm sido nesse sentido. É fundamental darmos atenção a formação e a capacitação de mais agentes transformadores da sociedade. 
